\title{
Extrathymic T-cell differentiation in vitro
}

\author{
Graham Pawelec
}

1 April 2004

The first 'Innovation' article in Nature Reviews Immunology ${ }^{1}$ discussed the introduction of a technique for the extrathymic generation of $\mathrm{T}$ cells in culture ${ }^{2}$, which was suggested as being a useful new tool for studying T-cell differentiation in a way that was not previously possible ${ }^{1,3}$. The originators of this technique showed that extrathymic differentiation from bone-marrow progenitors in vitro can be accomplished using the OP9 stromal cell line, ectopically expressing the Notch ligand delta-like 1 (REFS 1,2). It was stated that this allowed T-cell-differentiation processes to be studied in a simple cell-culture system for the first time. Although this might be true for mouse cells, it is not the case for human cells. Some years ago, we showed that CD34 $4^{+}$lineage-negative human haematpoietic progenitors could acquire mature T-cell characteristics in a thymus-free culture system. This depended on the presence of peripheral-blood mononuclear cells (PBMCs) as feeder cells, cytokine cocktails and the use of serum-free media. Given the importance of delta-like 1, identified in the mouse system, and the fact that Notch ligands, including this one, are expressed by antigen-presenting cells ${ }^{4}$, one could ask why previous attempts by others to establish extrathymic T-cell-differentiation systems using PBMCs were less successful ${ }^{5-7}$. We suggest that the reason for such failures was probably the choice of culture medium and, to a lesser extent, the choice of cytokine cocktail and feeder cells. We tested many different formulations over the years, at first containing human serum or fetal-calf serum, with little success. We also tested many serum-free formulations, with equal lack of success. However, the use of the then newly developed X-Vivo 10 medium from BioWhittaker allowed development, for the first time, of $\mathrm{T}$ cells in the absence of thymic components in a limitingdilution cloning system. It was necessary to include stem-cell factor (SCF), fms-related tyrosine kinase 3 ligand (FLT3L), interleukin-2 (IL-2) and IL-3 in the cytokine cocktail. Cloning efficiencies were markedly increased by additional inclusion of oncostatin M or IL-7 (REF. 8). Feeder cells consisted of irradiated (at a dose such that no cells escaped proliferation blockade after irradiation) PBMCs pooled from 20 different donors. During the cloning procedure, these cells would have interacted with each other as a multi-way mixed-lymphocyte culture, resulting in cytokine release, and macrophage and dendritic-cell activation. The purity of the starting haematopoietic-cell population and the high cloning efficiency that could be achieved ruled out the possibility that the $\mathrm{T}$ cells isolated were derived from contaminants in the starting population. Derived T cells were not autoreactive, suggesting that negative selection had taken place in a system where the feeder cells did express MHC class II or class I molecules, unlike the OP9 mouse system recently discussed ${ }^{1}$. Derived clones were mostly $\mathrm{CD}^{+} \alpha \beta$-T-cell receptor 2 (TCR2) ${ }^{+}$, expressed a wide range of antigen-receptor clonotypes, responded to mitogenic stimulation by proliferation and cytokine release ${ }^{8}$, and had the cell-surface markers and growth characteristics ${ }^{9}$ typical of human $\mathrm{CD}^{+}{ }^{+} \mathrm{T}$-cell clones. Currently, human T-cell clones derived in this manner are being examined ${ }^{10}$ by European Union-supported consortia focused on ageing of the immune system, ImAginE and T-CIA (see further information for websites). Perhaps because of our focus on immunogerontology, and exclusively in humans, these previous findings might have been overlooked.

\section{Graham Pawelec}

University of Tübingen Center for Medical Research (ZMF), Waldhörnlestr. 22, D-72072 Tübingen, Germany.

e-mail: graham.pawelec@uni-tuebingen.de

\section{FURTHER INFORMATION}

ImAginE, Immunology and Ageing in Europe:

http://www.medizin.uni-tuebingen.de/imagine/

T-CIA, T Cell Immunity and Ageing:

http://www.medizin.uni-tuebingen.de/t-cia/

European Searchable Tumour Line Database:

http://www.medizin.uni-tuebingen.de/estdab/

Graham Pawelec's homepage: http://www.medizin.uni-tuebingen.de/tati/

\section{References}


1. Zúňiga-Pflücker, J. C. T-cell development made simple. Nature Rev. Immunol. 4, 6772 (2004).

2. Schmitt, T. M. \& Zúňiga-Pflücker, J. C. Induction of T cell development from hematopoietic progenitor cells by delta-like-1 in vitro. Immunity 17, 749-756 (2002).

3. Lehar, S. M. \& Bevan, M. J. T cell development in culture. Immunity 17, 689-692 (2002).

4. Yamaguchi, E. et al. Expression of Notch ligands, Jagged 1, 2 and Delta 1 in antigen presenting cells in mice. Immunol. Lett. 81, 59-64 (2002).

5. Tjonnfjord, G. E., Veiby, O. P., Steen, R. \& Egeland, T. T lymphocyte differentiation in vitro from adult human prethymic $\mathrm{CD}^{+} 4^{+}$bone marrow cells. J. Exp. Med. 177, 15311539 (1993)

6. Galy, A., Verma, S., Barcena, A. \& Spits, H. Precursors of $\mathrm{CD} 3^{+} \mathrm{CD} 4^{+} \mathrm{CD} 8^{+}$cells in the human thymus are defined by expression of CD34 - delineation of early events in human thymic development. J. Exp. Med. 178, 391-401 (1993).

7. Freedman, A. R. et al. Generation of human T lymphocytes from bone marrow $\mathrm{CD} 34^{+}$ cells in vitro. Nature Med. 2, 46-51 (1996).

8. Pawelec, G. et al. Extrathymic T cell differentiation in vitro from human $\mathrm{CD}_{3} 4^{+}$stem cells. J. Leukocyte Biol. 64, 733-739 (1998).

9. Pawelec, G. et al. Finite lifespans of T cell clones derived from $\mathrm{CD}_{3} 4^{+}$human haematopoietic stem cells in vitro. Exp. Gerontol. 34, 69-77 (1999).

10. Pawelec, G., Barnett, Y., Mariani, E. \& Solana, R. Human CD4 ${ }^{+}$T cell clone longevity in tissue culture. Exp. Gerontol. 37, 265-269 (2002). 